emerged during the past fifteen years or so has been that of a small number of centrally-situated laboratories. Most scientifically advanced countries have their own nationally-funded magnet laboratories, the exception being Great Britain which has neither laboratory nor plans for one. Typically, a laboratory of this kind has available about 10 MW of d.c. power and cooling facilities; it offers steady magnetic fields of up to about $15 \mathrm{~T}$ to those prepared to perform their experiments away from home. Many laboratories are now seeking to increase the field strength which they can reach and it seems that the practical limit, which at present is probably about $30 \mathrm{~T}$, is within sight of being reached. Beyond this figure problems of stress and heat transfer become so acute that the only practical solution is to use pulse techniques.

The subject of pulsed magnetic field systems has a distinguished ancestry with names such as Fabry, Perot, Cockroft and Kapitza figuring largely in its development. Within the past fifteen years or so the generation of high intensity pulsed fields has been the subject of intense activity in the laboratories of many atomic energy authorities largely because of the potential use of magnetic fields in the containment of plasmafusion devices. An immense body of experimental information and theoretical understanding has been built up, much of it contained in internal reports and rarely collected together in a systematic way.

One of the most distinguished of these laboratories is at Frascati, Italy. It is run under the auspices of the European Atomic Energy Commission and the Comitato Nazionale Energia Nucleare. Its high field research group is led by the author of this book and into it he has distilled eight years' experience with pulsed magnetic field systems. Although written from the standpoint of an experimentalist the theory is developed $a b$ initio and in full. The basic theory begins with the calculation of quasistationary magnetic fields and is then extended to cover magnetic diffusion theory. There follow sections on heating and stress effects in current-carrying conductors. Energy storage systems, the design of coils, flux compression systems including the use of implosive techniques, are all treated in detail. The final chapters deal with measurement techniques and the behaviour of conductors at high energy densities. There is an exhaustive list of references.

This is a treatise and is in every sense worthy of the title. It will undoubtedly become the "bible" for all those engaged in research involving pulsed magnetic fields. Would that every author delayed the writing of his book until he had as much to say as Dr Knoepfel.

E. W. LEE

\section{Geochemical Method}

Modern Methods of Geochemical Analysis. Edited by Richard E. Wanerdi and Ernst A. Uken. Pp. xviii +397. (Plenum: New York and London, 1971.) $\$ 25.20$.

THIS text represents yet another attempt to summarize the large variety of analytical techniques, both chemical and mineralogical, used in geochemistry.

The introductory section opens with a definition of geochemistry and an outline of the broad fields of application of geochemical analysis. Surely the science is past the stage of requiring a definition, nor is there need to justify geochemical analysis as an investigative method in the earth sciences. A useful, though elementary, chapter on statistics follows the introduction. Apart from defining statistical parameters, this contains a limited number of examples of the use of statistics with respect to the need or otherwise of replication in analysis. Succeeding chapters, written by authorities in the particular fields, deal with various methods of analysis. In sequence they include: "Chemical Analysis and Sample Preparation," "IonExchange Chromatography", "Colorimetry", "Infrared Spectrometry", "Optical Emission Spectroscopy", "Atomic Absorption," "X-ray Techniques," "Radiometric Techniques," "Nuclear Activation Analysis" and "Mass Spectrometry." The criteria underlying the choice of methods must remain a mystery. For example, why is ionexchange chromatography included but not paper, thin-layer or gas chromatography or, in connexion with mass spectrometry, why is age-determination mass spectrometry excluded?

The chapters basically cover similar aspects including historical development, basic principles, sample preparation and presentation, apparatus, techniques, sensitivity, precision and accuracy, geochemical applications and recent and future developments. $\mathrm{Be}$ cause of the wide variety of authors, however, the description of each method varies very widely within the above framework. Some authors stress basic principles while others, much more usefully in the context of this book, stress the applications and developing utility of the technique, illustrating their discourse with well chosen examples. Clearly principles, which have changed but little over a number of years, could be fully covered by reference to authoritative and definitive texts. This approach is adopted by many of the authors who specifically recommend further reading, particularly on this aspect. The opportunity for further reading is certainly present, as each chapter is endowed with an extensive, up to date bibliography. In most chapters the advantages and disadvantages of particular techniques are evaluated, and in some instances the information allows an assessment of the relative merits, and cost, of complementary or alternative methods. One useful facet introduced by many authors deals with probable future developments. These techniques, still in their experimental phase, may ultimately become important analytical methods.

As a general reference work this book should be a useful addition to most libraries; priced at $\$ 25.20$, however, it is difficult to recommend for individual purchase.

D. M. HiRsT

\section{Organic Electrochemistry}

Electrochemical Reactions in Nonaqueous Systems. By Charles K. Mann and Karen K. Barnes. (Monographs in Electroanalytical Chemistry and Electrochemistry.) Pp viii +560 . (Dekker: New York, October 1970.) \$34.50; $£ 16.40$.

IN the past decade, there has developed a clear need for an authoritative and well balanced text on organic electrochemistry to provide a common base for both the organic chemist and the electrochemist working in this area. Unfortunately, neither this book nor the other recent texts by organically inclined authors comes close to filling the gap. Indeed, this volume is concerned essentially with the electrochemistry of organic compounds in non-aqueous media; the single final chapter on inorganic compounds provides insufficient justification for a wider claim. An introductory chapter on the interpretation of electrochemical measurements is included to help readers who have insufficient backgrounds in electrochemistry. It is too short to be of much value in this respect, and its main utility is in giving data on the behaviour of background electrolytes and reference electrodes in a number of solvent systems.

The authors state that the book is based on a literature search covering the period to the end of 1968 . The result is a systematic but rather uncritical review of this literature together with a large and useful compilation of the electrochemical reaction potentials of many compounds. There are chapters dealing separately with particular classes of compounds and no further attempt is made to show the underlying unity of the subject nor to discuss the many urgent and unanswered questions in the field. One looks in vain for the authoritative touch, the panoramic view that might delineate the skeletal structure on which the great mass of data can be hung, so that the basic chemistry is emphasized. Thus the reader is neither stimulated nor guided but merely in- 